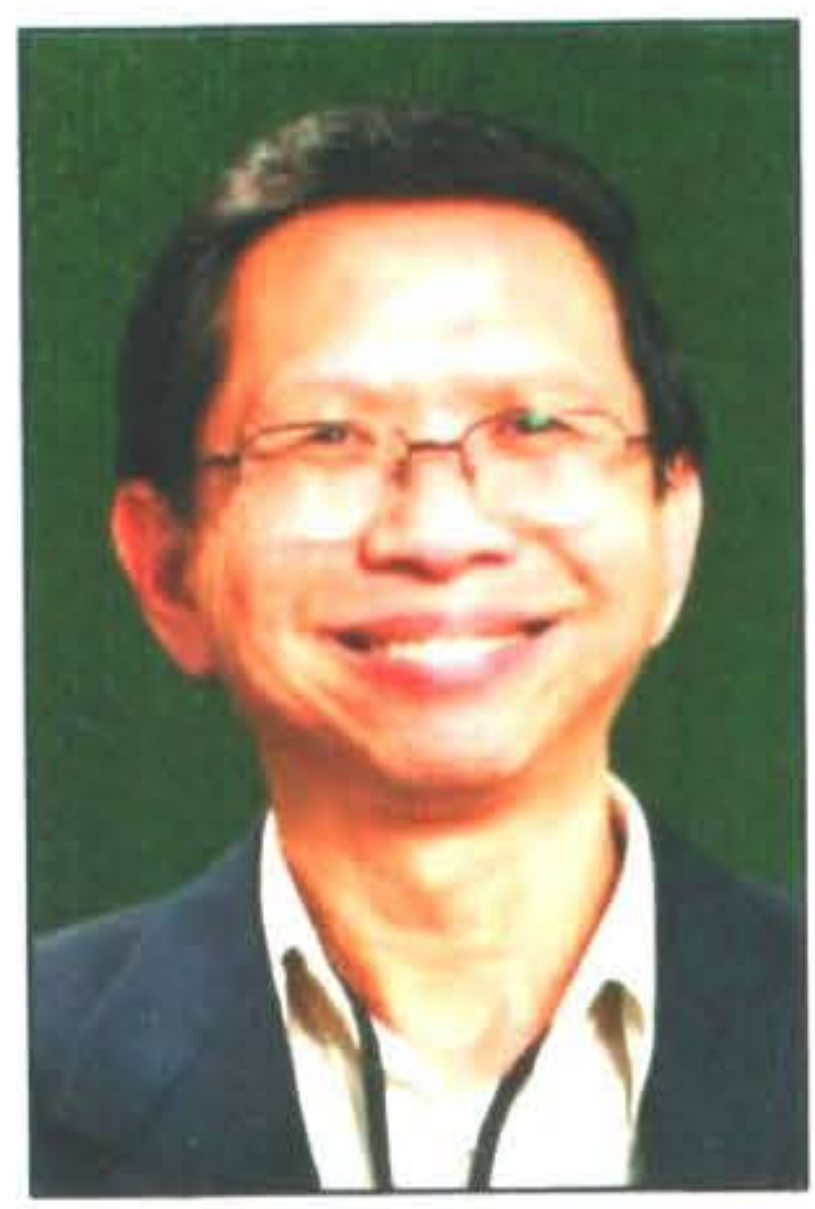

\title{
PERCEPTIONS OF FARM STRESSORS AMONG NEW ZEALAND FARM MANAGERS
}

\author{
Ang (Andy) Huat Bin
}

University of Auckland

The New Zealand primary sector not only has one of the highest rates of job-related injuries and illness, but also the Accident Compensation Corporation has paid one of the highest rate claims of more than NZ\$22 million in 2004 and 2005 (ACC. 2006). There are a high number of cases among farmers and farm employees who are involved in fatalities, injuries and ill health where stress and fatigue are the major contributors. Stress-related illnesses, in particular attempted and successful suicides, are now some of the major concerns and have attracted increased interest from academics abroad.

The aim of the research is to examine the extent of occupational stress in farming. The survey was piloted and through extensive interviews and farm visits. The pilot study is part of a larger questionnaire survey of self-reported 1041 participants. The Edinburgh Farming Stress Inventory (Deary, Willock, \& McGregor, 1997) and the General Health Questionnaire (GHQ-12) are utilized in the questionnaire survey.

The preliminary analysis discloses the insignificant in the level of strain with non-farming population. Further, the demographic variables such as mumber of herds, marital status, age group, occupational status and size of the farm are found to be insignificant factors for contributing towards stressors-strains. However, there is significant score differences in the perceived stressors between men and women. The individual characteristic has shown to have greater importance in determining the psychiatric disturbance associated with stress.

The contribution of this research is increased understanding of the causes and consequences of occupational stress in New Zealand farming industry. Further, the outcome will inform practices to identify areas where the industries can make improvements, be used in recruiting and selection programs and assist individuals in career planning.

\section{Background}

The New Zealand primary sector contributes more than $53 \%$ of the New Zealand merchandise exports in 2006 (MAF. 2007). The sustainable growth of this sector has provided employment opportunity, created wealth and a better lifestyle for farm managers ${ }^{1}$. However, the restructuring of the farm economy, which began in the mid-1980s, imposed severe adjustment pressures on all farm sectors. The impact of the agricultural policy reforms has been linked to high injuries and illness. including occupational stress. There are a high number of cases among farm managers and farm employees who are involved in fatalities, injuries and ill health where stress and fatigue are the major contributors. Stressrelated illnesses have emerged as a major concern and attracted increased interest from academics abroad. Further, there has been growing recognition that farm managers experience some of the highest levels of stress compared to their counterparts in the service or manufacturing sectors (Federated Farmers of NZ, 2006; MAF, 2006). Farm managers are critical for New Zealand agriculture, and different from those managers in industrial or service organizations.
There is a considerable body of research available on stress which is restricted to comparing the manufacturing and service sectors (Kinman, 2001: Cooper \& Marshall, 1976). For example, a survey by Kalliath, O'Driscoll, and Brough (2004) on the level of stress among the New Zealand workers from diverse industry, which include financial, retail, manufacturing, tourism and service industries. However, there is lack of empirical evidence on the extent of occupational stress in the New Zealand primary sector, particularly in the primary industry. Hence, it is necessary to examine the literature on job stress and stressors to understand the farm managers problems and how they are coping with the farm work.

\section{Occupational Stress in the Primary Sector}

Occupational stress is not the specific problem of one sector but pervades throughout the agriculture industry, although some groups are able to handle stressful situation (Lobley et al. 2004). For example, livestock farmers are more stressed than arable farmers (Boulanger, Gilman, Deaville, \& Pollock, 1999). Further, Walker \& Walker (1987) found that the stress levels vary among farmers 
who operate in different types of farms. Those farmers who work in mixed farms (livestock and grain) and dairy farms showed higher stress levels than those who operate in grain farms. The key issues for farm managers that have the potential to causes stress are as follows:

\section{The size of the farm}

A strong seasonal pattern with fluctuating demands for workers

Uncontrollable events such as weather and economic factors

Government policy, legislations, and regulations

Farming is a complex way of living that creates stressful life conditions among farmers (Melberg, 2003). Research shows that the relatively small farm owners experience greater stress (Hawton, Fagg, Simkin, Harriss, \& Malmberg, 1998). However, little research has been done on the effect of stress on New Zealand small to medium farm owners. The experience of stress is especially problematic as most farm managers who own farms, employ few staff, thus are working harder. In essence, the primary responsibility for running the entire farm rests on the shoulders of the farm owners/managers.

As the dairy, beef/sheep, and horticultural sector has a strong seasonal pattern, the demands for workers fluctuate. The widespread adoption of 'Once-a-day' milking and recently introduced Automated Milking System in the dairy industry would have a major implication for a reduced demand for labour and substantially improve lifestyle (Tipples, Wilson, Edkins, \& Sun, 2006).

Labour needs vary from one season to another in the industry. The availability of labour is most stressful among the farm owners during the peak season (Tipples, 2001). Every year the horticulture sector (e.g., fruit and vegetable industries) employs thousands of seasonal workers to harvest, pack and sort, and prune the trees. More jobs are available when the pipfruit harvest (e.g., apples) is at its peak season (Horticulture NZ, 2007). The peak season, in particular the calving period in dairy production and harvesting or planting in the horticulture sector is more stressful than other seasons (Lobley, Johnson, Reed, Winter, \& Little, 2004). Since the weather is an uncontrollable event, the timing of bad weather may have a major impact during the peak season on the success of the business (Deary, Willock, \& McGregor, 1997). For example, the drought-stricken Hawkes Bay farmers are experiencing emotional states of distress (Anderton, 2007). Further, these sectors have trouble in recruitment and retention because they provide poor remuneration and employment practices, and make some less skilled jobs unattractive (Baker, 2002). On the contrary, the employers who possess positive attitudes toward their staff would experience low turnover and improve job satisfaction (Tipples, 2001).

Due to the continuing changes in farming practices due to government deregulations and the external environment, occupational stress may be predicted to continue in the foreseeable future (Booth \& Lloyd, 2000). The consequences of increased workloads and working harder amongst New Zealand farm managers have come about in part as a result of the Amendment to the Health and Safety in Employment Act 2000 and Resource Management Act (Pedersen, 2007).

\section{Literature Review}

\section{Job Stress}

Stressful work activity has been associated with specific occupations. Any type of occupation has been found to lead to some negative effects on workers, but certain work activities are more likely to lead to be more stressful than other activities (Koslowsky, 1998). Early research on stressful occupations mainly concentrated on policing and nursing, and viewed stress as a simplistic causal relationship between stressors and strains. Recently there have been attempts to expand the research on occupational stress to include other industries and incorporate other disciplines (Lo \& Lamm, 2004). The stressor measurement found in most of the literature concerns job stressors among employees in the organization. These studies focus on employed staff in a range of occupations, such as in the university, church, factory and school (Chen \& Spector, 1991), fire and police employees (Schaubroeck, Ganster \& Fox, 1992), and academic staff (Kinman, 2001). These numerous theories on work-related stress provide a broader understanding of occupational stress and its consequences.

Hence, stress by nature is not a detrimental to many aspects of an individual's work-life. Individuals differ in their ways of handling stress when confronted by environment stressors leading to maladaptive behaviour and stress-related illness. Difference kind of stresses has been linked to work environment (Cooper \& Marshall, 1976).

The organisational and environmental factors or stressors, such as the excessively high work demands, have been widely recognised as contributors to ill-health (Spector \& Jex, 1998; Bohle \& Quinlan, 2000; Cooper, Dewe, \& O'Driscoll, 2001; Devereux, Rydstedt, Kelly, Weston, \& Buckle, 2004). Moreover, Fletcher (1991) suggests that the stressor is the source of work-related stress that influences mental and physical health outcomes.

\section{The Impact of Farm Stressors}

Previous research on farm stressors identified that farmers have encountered some stressors that are specific to farming and not common to all occupations. Page and Fragar (2002) reported that the farm stressors identified include financial difficulties, administrative and legislative pressures, production fluctuations that affect supplydemand and family problems. Additionally, the three consistently cited farm stressors in literature are isolation, bureaucracy, and financial pressures (Lobley, et al. 2004). A more recent study on New Zealand farm managers by Ang, Lamm and Tipples (2008) highlighted a number of stressors and reoccurring themes in the analysis of the narrative data, which include government policies and 
regulations, economic factors, excessive workload and lack of skilled labour.

Almost $80 \%$ of the farmers are reporting psychological and physical symptoms commonly associated with farm stress. They reported a moderate to high frequency of occurrence symptoms of anxiety, fatigue, loss of temper, forgetfulness, concentration difficulties, back pain, and sleep disruption (Walker \& Walker, 1988). A study by Wallis, Dollard, and Ranzijin (2003) on dairy farmers in South Australia has revealed that $30 \%$ of dairy farmers showed a high level of distress that would justify assistance firom a mental health professional. In addition, the majority of farmers in Australia work long hours, $90.3 \%$ worked more than 40 hours per week and $4 \%$ worked more than 100 hours (Fragar \& Franklin, 2000). According to Booth and Lloyd (2000), poor coping skills among British farmers to deal with new government policies and bureaucracy, and media criticism could lead to ill health. Thus, there are increased psychological distress symptoms among farmers that are significantly correlated with the farm stressors.

Past research has found that stress can cause strain on an individual's emotions, thoughts, and their physical condition (Hurrell, Nelson, \& Simmons, 1998; Spector, Dwyer, \& Jex, 1988). For instance, farmers' personal resources that inadequately meet the demands of the environment (e.g., stressors), will react with personal distress (Walker \& Walker, 1987). Further, Walker \& Walker (1987) reported that Canadian farmers are experiencing a variety of occupational stressors that can lead to mentally distressed state.

\section{Research Questions}

Previous researchers have cited similar causes of farm stressors on farmers (Firth, Williams, Herbison, \& McGee, 2006; Alpass, et al. 2004; Pollock, et al. 2002; Deary, et al.1997; Eberhardt \& Pooyan, 1990). A review of the literature reveals a research question that requires further investigation.

Research Question 1: What are the contributing factors that lead to farm stressors among the rural farm managers?

Research Question 2: What are the demographic differences of rural farm managers in the stressor-strain relationship?

\section{Research Method}

\section{Instruments}

The Edinburgh Farming Stress Inventory (Deary, Willock, \& McGregor, 1997) and the General Health Questionnaire (GHQ-12) were utilized in the questionnaire survey. An essential first part of the study was to undertake a pilot survey in order to determine the appropriateness of the survey instrument.

\section{The General Health Questionnaire (GHQ-12)}

The General Health Questionnaire (GHQ-12) has been used in a number of ways: 1) in the UK to psychologically assess and compare farm managers who have been, or not been, affected by the impact of foot-and-mouth disease (Peck, Grant, Mcarthur, \& Godden, 2002) and 2) to indicate the extent of occupational stress amongst farm managers and their families (Booth \& Lloyd, 2000). Job stress (General Health Questioniare-12) is designed to assess psychological strain that composed of social dysfunction and anxiety/depression factors (Kalliath, O'Driscoll, \& Brough, 2004). The measurement of job stress has been proven widely used measurement of personality illness in psychology research. A General Health Questionnaire-12 (GHQ-12) score of 4 or above is the cutoff score indicate a significant mental health problem (Peck et al. 2002).

\section{Edinburgh Farming Stress Inventory}

Edinburgh Farming Stress Inventory instrument is anticipated to identify the different stressors experienced by New Zealand farm managers. A total of six domains consisting of 35 items to assess the farm-related stress have been identified in the inventory: 1) farming bureaucracy; 2) financial issues; 3) uncontrollable natural forces; 4) time pressures; 5) personal farm hazards; and 6) geographical isolation (Deary et al. 1997). The respondents are asked to rate the severity and frequency of occurrence of stressors that may adversely affect their psychological well-being.

\section{Procedures}

A pilot study was conducted in the first part of the study. The pilot study is intended to ensure that the proposed farm related stress instrument and its procedures will work in practice before being applied to a large sample of farmers. The outcome of the pilot survey was that several questionnaires were modified and administrated to approximately 6,000 farm managers who are members of the NZ Federated Farmers Inc. and Horticulture New Zealand. The 12 items in General Health Questionnaire12, were incorporated in New Zealand farm managers' survey as well as Edinburgh Farming Stress Inventory (Deary, Willock, \& McGregor, 1997). A set of General Health Questionnaire and Edinburgh Farming Stress Inventory questionnaires together with an additional questionnaire asking for demographic details were distributed to the farm managers by utilizing the farm organizations' database. The researcher will assure all information collected from the respondents is confidential, their privacy protected and no one will be identified in the report.

The Farmers Federation NZ Inc., which represents the majority of dairy/beef/sheep farm managers and Horticulture NZ, which represents the majority of horticultural farm growers distributed the questionnaires. To increase the response rate, both of these organizations recommended a variety of mediums to administer the survey questionnaire. The Federated Farmers has recommended an email survey as well as a postal survey 
to reach out to their members. On the other hand, the Horticulture NZ has proposed to utilise their "monthly orchardist's magazine" to inform their members. A study by Clayton, Applebee, and Pascoe (1996) demonstrated that the combination of both methods of data collection will increase the reliability of the survey instrument and response rate when it is analyzed and deduced.

\section{Findings}

\section{Descriptive Statistics}

A total of 1041 individual questionnaires were received from online survey, magazine and postal survey, giving a total response rate of $17.4 \%$. The sample consisted of (819) $80 \%$ men and (207) $20 \%$ women farm managers from diverse farming sectors. There were 580 participants from the dairy sector, 266 participants from the horticulture sector and 195 participants from the beef/sheep/arable/crop/forestry sectors. The data from diverse sectors of the farming industry were used to report assessment of the demographics statistics, such as gender, ethnicity, tenure, sickness, region, hours worked, and age. $86 \%$ of the respondents were farm owners with average age of 50 years, where $83.4 \%$ of were married. Less than $3 \%$ farm managers were divorced, widowed, defacto, or separated. $6 \%$ were never married. The average farm size was 370 hectares from all sector of the primary industry.

Demographic information is shown in Table 1 and Table 2.

Table1: Demographic information for the farm managers by frequency and percentage.

\begin{tabular}{|l|l|}
\hline Characteristic & Frequency (\%) \\
\hline Ethnicity $(\mathrm{n}=1028)$ & $916(88 \%)$ \\
NZ Pakeha & $16(1.5 \%)$ \\
NZ Maori & $46(4.4 \%)$ \\
New Zealander & $14(1.3 \%)$ \\
European & $2(2 \%)$ \\
African & $1(0.1 \%)$ \\
Asian & $32(3.1 \%)$ \\
Others & \\
\hline Marital Status $(\mathrm{n}=1021)$ & $62(6 \%)$ \\
Never married & $868(83.4 \%)$ \\
Married & $11(1.1 \%)$ \\
Civil Union & $13(1.2 \%)$ \\
Separated & $30(2.9 \%)$ \\
Divorced & $24(2.3 \%)$ \\
Widowed & $13(1.2 \%)$ \\
De Facto & \\
\hline Employment Status $(\mathrm{n}=1040)$ & $895(86 \%)$ \\
Farm owner & $65(6.2 \%$ \\
Farm manager & $57(5.5 \%)$ \\
Sharemilker & $4(0.4 \%)$ \\
Lower order sharemilker & $19(1.8 \%)$ \\
Other & \\
\hline
\end{tabular}

Table 2: Demographic information for farmers by mean

\begin{tabular}{|l|l|}
\hline Characteristic & Mean \\
\hline Age $(\mathrm{n}=1018)$ & 50 yrs old \\
\hline Avg. hrs worked/week $(\mathrm{n}=1001)$ & $54 \mathrm{hrs}$ \\
\hline Tenure $(\mathrm{n}=875)$ & 20 yrs \\
\hline Farm Size $(\mathrm{n}=1017)$ & 370 hectares \\
\hline No. of herds $(\mathrm{n}=604)$ & 560 \\
\hline No. of employees peak season $(\mathrm{n}=664)$ & 7 \\
\hline Sick-days/year $(\mathrm{n}=642)$ & 3 days \\
\hline
\end{tabular}

SPSS was tested to explore factors analysis of the job stress and Edinburgh Farming Stress Inventory variables. Associations among the items in the Edinburgh Farming Stress Inventory in the questionnaires were examined using principal components analysis with varimax rotation. The factor structures of the Edinbury Farming inventory and job stress were found to be similar loading to previous studies. The six domains or dimension of Edinburgh Farming Stress Inventory (stressors) are shown in Table 3.

\section{Table 3: Farm stressors scores}

\begin{tabular}{|l|l|}
\hline Domains & Mean $(\mathrm{n}=1034)$ \\
\hline Government Bureaucracy & 2.58 \\
\hline Unpredictable Factors & 2.49 \\
\hline Personal Hazards & 2.32 \\
\hline Time Pressure & 2.28 \\
\hline Finance & 2.16 \\
\hline Isolation & 1.41 \\
\hline
\end{tabular}

Figure 1 shows the severity of stressors and stress (RevGHQ2) relationship by sex. Both male and female farm managers experience the highest impact of government bureaucracy which is a prominent source of stress in farming. "These stressors have a number of domino and cumulative effects, thus creating layer upon layer of stress" (Ang et al., 2008, p. 91). The analysis revealed that the high effect of stressor lead to high strain (Ang, Wilson, et al. 2009, in press).

On contrary, isolation is not a major source stress for any male farm managers surveyed. Men farm managers reported stressful in unpredictable events, such as bad weather and market conditions. However, a few female reported isolation as a source of stress in farming. Moreover, female farm managers reported more stress than did men in the domain of government bureaucracy, finance, and personal hazards. 
Figure 1: The stressors-strain relationship by sex

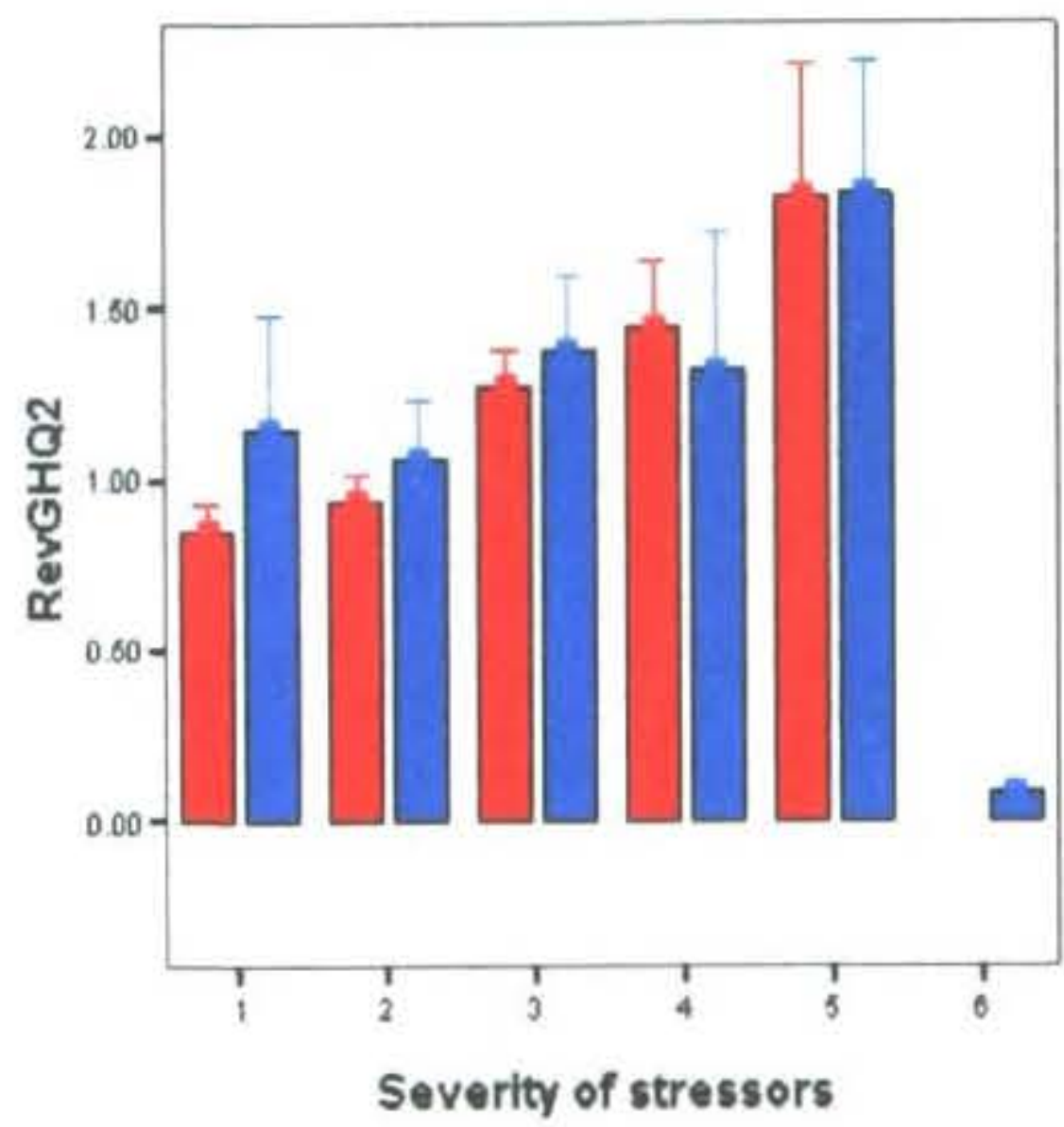

The results of the Pearson correlation have shown that the variables were in expected direction. The job stress items were factor-analyzed using principal components analysis and an oblimin rotation procedure. The farm managers $(n=1041)$ reported a mean score of 1.1 $(\mathrm{SD}=0.93)$ which indicate low level of strain.

Coefficients for internal consistency for job stress and farming stressors inventory were above the accepted threshold $(\alpha>0.70)$. The correlations of job strainsstressors relationship appear in Table 4.

Table 4: Correlations of the variables

\begin{tabular}{|c|c|c|}
\hline & Strains & Stressors \\
\hline Strains & 1 & $.44(* *)$ \\
\hline
\end{tabular}

** Correlation is significant at the 0.01 level ( 1 -tailed). $\mathrm{n}=1022$

The key statistics in one-way ANOVA is the F test of difference of mean. One of the assumptions of ANOVA is that the dependent variable is normally distributed. By testing one-way ANOVA on job stress as dependent variable and sex as independent variable, the job stress scale show a gender difference $(\mathrm{f}=19.01, \mathrm{df}=1,1020$, $\mathrm{p}<0.001$ ) with female score significantly higher strain than male farm manager.

A global strain score was calculated to examine the demographic variables of the farm managers. There were no significant differences in age groups $(F(4,916)=2.2$, $\mathrm{p}<0.07)$ nor any differences between farm type $(F(7,1028)=1.59, p<0.14)$.

\section{Conclusion}

The rural farm managers in the present sample report comparative moderate low source of stressors related to government bureaucracy, unpredictable factors, time pressure, and personal hazards. The uncontrollable natural forces factor is a useful generalization of the unpredictable or unfavourable weather that experience by New Zealand farm managers. For example, drought and frost experience by dairy/sheep/beef/deer and horticultural farm owners.

By examining stressors-strain variables together, it is possible to understand the risk factors for farm managers. The pattern of stress in farming is nearly identical to that „Seenchy al. 2004; Pollock, et al. 2002; Deary, et al.1997; Eberhardt "\& Pooyan, 1990).

\section{Implications of the Study}

What implications do these findings have for mental health services or farming organizations or agencies? This study has highlighted some of the specific issues that farm managers find stressful. Thus, the contribution of this research is increased understanding of the causes and consequences of occupational stress in the farming sector and potential screening aspects for career advising. The outcome will inform practices to identify areas where the industries can make improvements, be used in recruiting and selection programs, and to assist individuals in career planning.

\section{Area for Future Research}

This paper evaluated the source of stress in farming. This paper identified that source of stress could lead to strain among farm managers. The findings of this paper highlight the importance of further research on the impact of farm stressors due to changing labour market, unpredictable weather, and government regulations. Furthermore, since there are peak and low season in farming, the findings of this paper could be usefully tested at different season of the year where farm owners/farm managers/sharemilkers/orchardists may experience different sources and level of stress.

\section{Note}

1. Farm managers refer to the farm owners or those who manage the farm that do not belong to them.

\section{References}

Accident Compensation Corporation (2006, $1^{\text {st }}$ ed.) ACC Injury Statistics 2006, Wellington: Government Printer.

Alpass, F., Flett, R., Humphries, S., Massey, C., Morris, T. \& Long, N. (2004) Stress in dairy farming and the adoption of new technology. International Journal of Stress Management, 11 (3), 270-81.

Anderton, J. (2007). NZ Herald News HomepageMinistry of Agriculture \& Forestry. Retrieved June 17, 2007, from http://www.nzherald.co.nz/ organisation/story.cfm?o_id=117\&objectid=1044 4021 . 
Ang, H. B., Lamm, F. \& Tipples, R. (2008) The impact of stressors on the psychological wellbeing of New Zealand farmers and the development of an explanatory conceptual model. Policy and Practice in Health and Safety, 6(1), 79-96.

Baker, J. (2002) The Skills Employers Needed. In Maharey, S. WorkINSIGHT, 1, 6, Wellington: Department of Labour.

Bohle, P. \& Quinlan M. (2000) Managing occupational health and safety: a multidisciplinary approach (2nd ed.). Melbourne: MacMillan.

Booth, N. J., \& Lloyd, K. (2000) Stress in farming. International Journal of Social Psychiatry. 46, 67-73.

Chen, Y., \& Spector, P. E. (1991) Negativity affectivity as the underlying cause of correlations between stressors and strains. Journal of Applied Psychology, 76(3), 398-407.

Clayton P., Applebee, A., \& Pascoe, C. (1996) E-mail surveys: Old problems with a new delivery medium. LASIE, 27, 30-9.

Cooper, C. L., Dewe, P. J., \& O'Driscoll, M. P. (2001) Organizational stress: a review and critique of theory, research, and applications. Thousand Oaks: Sage.

Cooper, C. L., \& Marshall, J. (1976) Occupational sources of stress: A review of the literature relating to coronary heart disease and mental ill health. Journal of Occupational Psychology, 49, 11-28.

Deary, I. J., Willock, J., \& McGregor, M. (1997) Stress in Farming, Stress Medicine, 13, 131-6.

Devereux, J., Rydstedt, L., Kelly, V., Weston, P., \& Buckle, P. (2004) The role of work stress and psychological factors in the development of musculoskeletal disorders: The stress and MSD study, Surrey: Robens Centre for Health.

Eberhardt, B. J., \& Pooyan, A. (1990) Development of the Farm Stress Survey: Factorial Structure, Reliability and Validity. Education and Psychological Measurement, 50, 393-402.

Federated farmers of New Zealand (2006) Federated Farmers Update, Hamilton: FFNZ.

Fletcher, B. (1991) Work Stress, Disease, and Life Expectancy. New York: Wiley.

Firth, H.M., Williams, S. M., Herbison, G. P., \& McGee, R. O. (2006) Stress in New Zealand Farmers. Stress and Health. 23, 51-8.

Hawton, K., Fagg, J., Simkin, S., Harriss, L.,
Malmberg, A., \& Smith, D. (1998) Methods used for suicide by farmers in England and Wales. The contribution of availability and its relevance to prevention. The British Journal of Psychiatry, 173, 320-4.

Hurrell, J. J., Nelson, D. L., \& Simmons, B. L. (1998) Measuring job stressors and strains: Where we have been, where we are, and where we need to go. Journal of Occupational Health Psychology, 3(4), 368-89.

Kalliath, T., O'Driscoll, M., \& Brough, P. (2004) A confirmatory factor analysis of the General Health Questionnaire-12. Stress and Health, 20, 11-20.

Kinman, G. (2001) Pressure points: A review of research on stressors and strains in UK academics. Educational Psychology, 21(4), 473-92.

Koslowsky, M. (1998) Modeling the Stress-Strain Relationship in Work Settings. London: Routledge Progress in Psychology.

Lo, K. \& Lamm, F. (2004) 'Occupational Stress in the Hospitality Industry: an employment relations perspective' New Zealand Journal of Employment Relations, 30(1): 23-48.

Lobley, M., Johnson, G., \& Reed, M. with Winter, M. \& Little, J. (2004) Rural Stress Review Final Report. UK: Centre for Rural Research, University of Exeter.

Melberg, K. (2003) Farming stress and psychological well-being: the case of Norwegian farm spouses. Sociological Ruralis, 43, 1, 56-76.

Page, A. N., \& Fragar, L. J. (2002) Suicide in Australia farming, 1988-1997. Australia and New Zealand Journal of Psychiatry, 36, 81-5.

Peck, D.F., Grant, S., Mcarthur, W., \& Godden, D. (2002) Psychological Impact of Foot and Mouth Disease on Farmers. Journal of Mental Health, 11, 523-31.

Pedersen, C. (Winter, 2007) Federated farmers of New Zealand. Federated Farmers Update, Hamilton: FFNZ.

Pollock, L., Deaville, J., Gilman, A., \& Willock J. (2002) A Preliminary Study into Stress in Welsh Farmers. Journal of Mental Health. 11(2), 213 21.

Schaubroeck, J., Ganster, D. C., \& Fox, M. L. (1992) Dispositional affect and work-related stress. Journal of Applied Psychology, 77(3), 322-35.

Spector, P. E., \& Jex, S. M. (1998) Development of four self-report measures of job stressors and strain: Interpersonal conflict at work scale, 
organizational constraints scale, quantitative workload inventory, and physical symptoms inventory. Journal of Occupational Health Psychology, 3, 356-67.

Spector, P. E., Dwyer, D. J., \& Jex, S. M. (1988) Relation of job stressors to affective, health, and performance outcomes: a comparison of multiple data sources. Journal of Applied Psychology, 73(1), 11-9.

Tipples, R. (Oct., 2001) Getting and holding seasonal staff. Winepress, 102, p.18-24.

Tipples, R., Wilson, J., Edkins, R., \& Sun, Xiaomeng (2006) Future dairy farm employment in New Zealand - An application of the human capability framework. (Dairy insight research project). Lincoln University.

Wallis, A., Dollard, M., \& Ranzijn, R. (2003) Work stress and well-being of dairy farmers. Report to Dairy SA. Work and Stress Research Group, University of South Australia.

Walker, J., L., \& Walker, L. J. S. (1988) Self-reported stress symptoms in farmers. Journal of Clinical Psychology, 44(1), 10-6.

Walker, J., L., \& Walker, L. J. S. (1987) Stressors and symptoms predictive of distress in farmers. Family Relations. 36(4), 374-8.

\author{
Author \\ Ang (Andy) Huat Bin \\ $\mathrm{PhD}$ Candidate, School of Business - Management \\ Auckland University of Technology \\ Private Bag 92006 \\ Auckland 1142 \\ Huat-bin.Andy.Ang@aut.ac.nz
}

